\title{
Predictive value of plasma D-dimer levels in patients with advanced non-small-cell lung cancer
}

This article was published in the following Dove Press journal:

OncoTargets and Therapy

13 April 2015

Number of times this article has been viewed

\section{Yuezhen Wang ${ }^{1,2}$ \\ Zhun Wang',2}

'Department of Radiation Oncology, Zhejiang Cancer Hospital, Hangzhou, People's Republic of China; ${ }^{2}$ Zhejiang Key Laboratory of Radiation Oncology, Hangzhou, People's Republic of China
Correspondence: Yuezhen Wang Department of Radiation Oncology, Zhejiang Cancer Hospital, 38 Guangji Road, Hangzhou 3 I 0022, People's Republic of China

Tel +86 57I 88I2 2100

Fax +865718812 2100

Email zjzlyy123@163.com
Purpose: The relationship between plasma D-dimer level and the prognosis of advanced non-small-cell lung cancer (NSCLC) is not well studied. This study investigated the role of plasma D-dimer as a prognostic factor in advanced NSCLC.

Methods: The plasma D-dimer was measured in 1,931 newly diagnosed advanced NSCLC patients by enzyme-linked immunosorbent assay. Correlations between plasma D-dimer levels and other clinical parameters were analyzed. Survival curves were plotted using the Kaplan-Meier method. The Cox proportional hazard model was used for multivariate analysis.

Results: Plasma D-dimer concentrations were within the normal range in 1,393 patients $(72.1 \%)$ and elevated in 538 patients (27.9\%). The median overall survival was 11.5 and 8.8 months in the normal and high plasma D-dimer group, respectively $(P<0.001)$. The progression-free survival of first-line chemotherapy was 5.0 months and 4.4 months in the groups with normal and high levels of plasma D-dimer, respectively, $(P<0.001)$. By multivariate analyses, the elevated plasma D-dimer level was found to be an independent prognostic factor for poor survival (hazard ratio $=1.245 ; P<0.001$ ).

Conclusion: Plasma D-dimer is an independent determinant of poor prognosis in advanced NSCLC.

Keywords: plasma D-dimer, prognosis, non-small-cell lung cancer, performance status

\section{Introduction}

Plasma D-dimer is the smallest unique degradation product of cross-linked fibrin resulting from the proteolytic actions of plasmin. ${ }^{1}$ Plasma D-dimer levels have been shown to be elevated in patients with prostate cancer, ${ }^{2}$ colorectal cancer, ${ }^{3}$ lung cancer, ${ }^{4}$ and breast cancer. ${ }^{5}$ As plasma D-dimer levels are elevated after clot formation, the measurement of D-dimer is routinely used in conjunction with clinical parameters in the initial assessment of suspected acute venous thromboembolism.

There were many studies reporting the relationship between plasma D-dimer levels and the prognosis of solid cancer. ${ }^{2-7}$ D-dimer levels have been found to be significantly higher in lung cancer with poor prognosis. ${ }^{8,9}$ However, for most of the studies, the correlations between the plasma D-dimer levels and prognosis of lung cancer were analyzed based on data such as the stage of the cancer (I-IV) and different histologic subtypes (both non-small-cell lung cancer [NSCLC] and small cell lung cancer) ${ }^{8-15}$ The data from the advanced NSCLC is lacking.

This study reviewed a series of consecutive patients with advanced NSCLC, newly diagnosed in a single institution, to detect the relationship between the plasma D-dimer levels of patients and prognosis. 


\section{Patients and methods}

A total of 2,760 patients who were pathologically or cytologically diagnosed as stage IV NSCLC between January 2000 and January 2011 at Zhejiang Cancer Center were identified. Lung cancer staging was performed for all patients according to the 7th TNM classification. The inclusion criteria were as follows: confirmed metastases as observed on emission computed tomography, magnetic resonance imaging, or computed tomography; did not received chemotherapy, radiotherapy, and other treatment before the D-dimer examination. Patients with a history of venous thrombosis or anticoagulation therapy, hypertension, cardiovascular and cerebrovascular disease, diabetes, acute or chronic inflammatory disease, or previous malignancy were excluded from the current study. Totally, 1,931 patients were included in the current study. The Ethics Committee at Zhejiang Cancer Hospital approved the study.

\section{Measurement of D-dimer}

Patients' blood samples were obtained at presentation and processed immediately. The D-dimer was assayed with a latex-enhanced immunoturbidimetric assay in the clinical laboratory of the Shanghai Cancer Center using an Olympus AU640 automatic analyzer (Olympus Corporation, Tokyo, Japan). Commercially available reagents were used to measure the D-dimer levels (Daiichi Seiyaku Co Ltd, Tokyo, Japan). The reference value for D-dimer was less than $0.5 \mu \mathrm{g} / \mathrm{mL}$. The normal plasma levels of D-dimer range from 0 to $0.5 \mu \mathrm{g} / \mathrm{mL}$. Hence, a serum plasma D-dimer concentration of $>0.5 \mu \mathrm{g} / \mathrm{mL}$ was considered positive.

\section{Follow-up}

None of the patients who had been evaluated for overall survival (OS) were lost to follow-up. The median follow-up period was 18.0 months (range, 2.0-48 months). The last follow-up date was December 31, 2013.

\section{Statistical analysis}

Survival was recorded from the first day of diagnosis to the date of death or the last follow-up visit. Survival curves were calculated using the Kaplan-Meier method. Statistical analysis was performed using SPSS, version 16.0 (SPSS Inc, Chicago, IL, USA).

\section{Results}

\section{Clinical characteristics}

The relationship between the plasma D-dimer levels and clinical characteristics is listed in Table 1 . There were
Table I Comparison of clinical characteristics between normal and high D-dimer levels in patients with advanced non-small-cell lung cancer

\begin{tabular}{|c|c|c|c|}
\hline Variables & $\begin{array}{l}\text { Normal D-dimer } \\
(n=1,393)\end{array}$ & $\begin{array}{l}\text { High D-dimer } \\
(n=538)\end{array}$ & $P$-value \\
\hline Sex & & & 0.35 \\
\hline Male & 947 & 378 & \\
\hline Female & 444 & 160 & \\
\hline Age & & & 0.85 \\
\hline$\geq 65$ & 558 & 213 & \\
\hline$<65$ & 835 & 325 & \\
\hline Smoking history & & & 0.54 \\
\hline Yes & 726 & 272 & \\
\hline No & 667 & 266 & \\
\hline Histology & & & 0.44 \\
\hline Adenocarcinoma & 747 & 299 & \\
\hline Others & 646 & 239 & \\
\hline TNM stage & & & 0.17 \\
\hline $\mathrm{Mla}$ & 95 & 29 & \\
\hline MIb & 1,298 & 509 & \\
\hline PS & & & 0.0004 \\
\hline $0-1$ & 1,023 & 351 & \\
\hline $2-3$ & 370 & 187 & \\
\hline \multicolumn{2}{|c|}{ First-line chemotherapy } & & 0.16 \\
\hline Yes & 871 & 355 & \\
\hline No & 522 & 183 & \\
\hline
\end{tabular}

Abbreviation: PS, performance status.

1,325 males and 604 females. One thousand three hundred and ninety-three patients $(72.1 \%)$ had normal levels of plasma D-dimer, 538 patients $(27.9 \%)$ had high levels of plasma D-dimer. There were no significant differences in plasma D-dimer levels and clinical factors such as age, sex, histology, smoking history, and TNM stage. There were significant differences in performance status (PS) between the normal- and high-level D-dimer groups.

\section{Factors affecting overall survival: by univariate and multivariate analyses}

Univariate analyses were performed using the Kaplan-Meier method to assess the predictive capacity of each tested variable (Table 2). Sex $(P<0.001)$, smoking history $(P<0.001)$, histology $(P=0.002)$, TNM stage $(P<0.001)$, PS $(P<0.001)$, and D-dimer level $(P<0.001)$ were predictive of OS.

As Figure 1 demonstrates, there was a significant difference in median OS between the normal- and high-level D-dimer groups (11.5 months vs 8.8 months; $P<0.001$ ). The difference in progression-free survival (PFS) between the groups with normal and high $\mathrm{D}$-dimer levels was statistically significant (5.0 months vs 4.4 months, $P<0.001$ ) (Figure 2). 
Table 2 Univariate analysis of the patient survival according to the clinicopathologic characteristics

\begin{tabular}{|c|c|c|c|}
\hline Variables & Number & $\begin{array}{l}\text { Median overall } \\
\text { survival (months) }\end{array}$ & $P$-value \\
\hline Sex & & & $<0.001$ \\
\hline Male & I,325 & 9.8 & \\
\hline Female & 604 & 12.8 & \\
\hline Age & & & 0.078 \\
\hline$\geq 65$ & 771 & 10.2 & \\
\hline$<65$ & 1,160 & 11.7 & \\
\hline Smoking history & & & $<0.001$ \\
\hline Yes & 998 & 9.2 & \\
\hline No & 933 & 12.3 & \\
\hline Histology & & & 0.002 \\
\hline Adenocarcinoma & I,046 & 11.5 & \\
\hline Others & 885 & 10.0 & \\
\hline TNM stage & & & $<0.001$ \\
\hline $\mathrm{Mla}$ & 124 & 11.2 & \\
\hline MIb & $\mathrm{I}, 807$ & 9.8 & \\
\hline PS & & & $<0.001$ \\
\hline $0-1$ & I,374 & 12.4 & \\
\hline$\geq 2$ & 557 & 8.5 & \\
\hline D-dimer & & & $<0.001$ \\
\hline Normal & 1,393 & 11.5 & \\
\hline High & 538 & 8.8 & \\
\hline
\end{tabular}

Abbreviation: PS, performance status.

Three hundred and fifty-five among the 538 patients with high D-dimer levels at diagnosis received first-line chemotherapy. D-dimer was collected from 212 patients after two cycles of chemotherapy. D-dimer levels decreased in 63 patients and increased in 149 patients. The difference

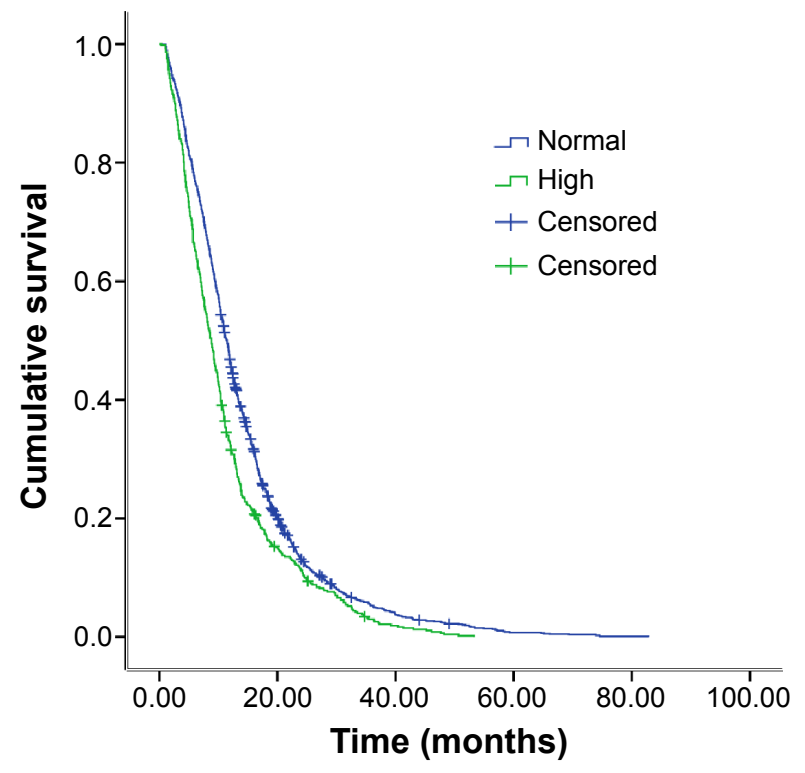

Figure I Kaplan-Meier estimates of the survival probabilities between normal and high D-dimer level.

Notes: I I.5 months vs 8.8 months, $P<0.001$.

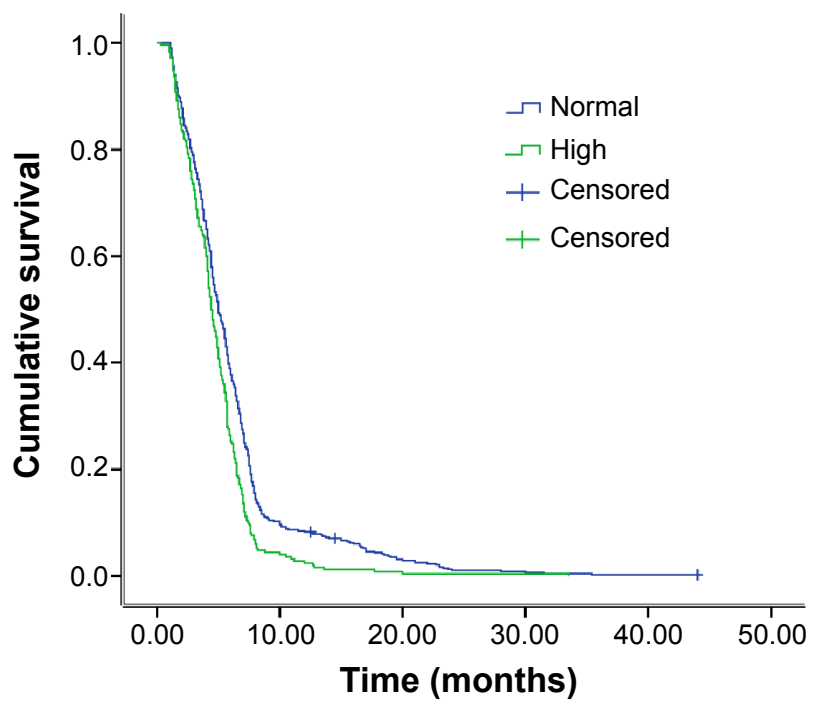

Figure 2 Kaplan-Meier estimates of the progression-free survival probabilities between normal and high D-dimer level.

Notes: 5.0 months vs 4.4 months, $P<0.00$ I.

in PFS between the groups with increased and decreased D-dimer level was statistically significant (4.0 months vs 4.8 months; $P=0.002$ ). The median survival time was 8.6 months and 9.5 months for the patient groups with high and low D-dimer levels, respectively, $(P=0.040)$.

A multivariate Cox's regression model was constructed considering age, sex, smoking history, histology, TNM stage, PS, and D-dimer level as variables. Smoking history, TNM stage, PS, and D-dimer level qualified as independent prognostic factors (Table 3 ).

\section{Discussion}

To the best of our knowledge, this is the largest study evaluating the clinical significance of plasma D-dimer levels in predicting survival in advanced NSCLC patients. By multivariate analyses, plasma D-dimer level was found to be a significant, independent prognostic marker for advanced NSCLC.

Table 3 Multivariate survival analysis for overall survival

\begin{tabular}{llll}
\hline Variables & HR & $\begin{array}{l}\text { 95\% confidence } \\
\text { interval }\end{array}$ & P-value \\
\hline Sex & 0.926 & $0.808-1.061$ & 0.270 \\
Age & 0.965 & $0.877-1.061$ & 0.458 \\
Smoking history & 1.921 & $1.331-2.917$ & 0.041 \\
Histology & 0.976 & $0.888-1.073$ & 0.640 \\
TNM stage & 0.356 & $0.316-0.401$ & 0.000 \\
PS & 2.061 & $1.616-2.514$ & 0.000 \\
D-dimer levels & 1.246 & $1.125-1.379$ & 0.000 \\
\hline
\end{tabular}

Abbreviations: HR, hazard ratio; PS, performance status. 
Previous research has found that D-dimer levels are correlated with tumor invasion, lymph node involvement, TNM stage, and tumor progression in different tumor types. ${ }^{2-7}$ In our study, there was no significant correlation of D-dimer levels to histological type, smoking history, or sex, however, our data revealed that D-dimer levels were related to the patient's PS in advanced NSCLC, an observation consistent with a previous research result. ${ }^{15}$

Previously, only one study by Antoniou et $\mathrm{al}^{4}$ with 52 patients showed elevated plasma D-dimer levels and was associated with reduced PFS. In this study, we found high plasma D-dimer levels as a determinant of shorter PFS in first-line chemotherapy of advanced NSCLC, and decreased D-dimer levels may predict the PFS and OS.

The median OS was shorter in patients with high D-dimer levels than that in patients with the same D-dimer levels in two meta-analysis studies. ${ }^{8,9}$ However, most of patients in the two meta-analysis were in early or locally advanced stages, and no study focused on advanced NSCLC. In the current study, we showed that high plasma D-dimer level is associated with decreased OS in patients with advanced NSCLC.

Our study is limited by its retrospective design over a long period. In addition, D-dimer levels were measured only once at study inclusion. However, with few advanced NSCLC cases in previous studies, our retrospective study may also be considered meaningful.

In conclusion, we suggest that plasma D-dimer levels can be used as a prognostic factor in advanced NSCLC patients. High D-dimer levels indicate poor prognoses by reducing the PFS and OS.

\section{Disclosure}

The authors report no conflicts of interest in this work.

\section{References}

1. De Buyzere M, Philippé J, Duprez D, Baele G, Clement DL. Coagulation system activation and increase of D-dimer levels in peripheral arterial occlusive disease. Am J Hematol. 1993;43(2):91-94.

2. Knowlson L, Bacchu S, Paneesha S, et al. Elevated D-dimers are also a marker of underlying malignancy and increased mortality in the absence of venous thromboembolism. J Clin Pathol. 2010;63(9):818-822.

3. Blackwell K, Hurwitz H, Liebérman G, et al. Circulating D-dimer levels are better predictors of overall survival and disease progression than carcinoembryonic antigen level in patients with metastatic colorectal carcinoma. Cancer. 2004;101(1):77-82.

4. Antoniou D, Pavlakou G, Stathopoulos GP, et al. Predictive value of D-dimer plasma levels in response and progressive disease in patients with lung cancer. Lung Cancer. 2006;53(2):205-210.

5. Dirix LY, Salgado R, Weytjens R, et al. Plasma fibrin D-dimer levels correlate with tumour volume, progression rate and survival in patients with metastatic breast cancer. Br J Cancer. 2002;86(3):389-395.

6. Altiay G, Ciftci A, Demir M, et al. High plasma D-dimer level is associated with decreased survival in patients with lung cancer. Clin Oncol (R Coll Radiol). 2007;19(7):494-498

7. Raj SD, Zhou X, Bueso-Ramos CE, et al. Prognostic significance of elevated D-dimer for survival in patients with sarcoma. Am J Clin Oncol. 2012;35(5):462-467.

8. Ma X, Li Y, Zhang J, et al. Prognostic role of D-dimer in patients with lung cancer: a meta-analysis. Tumour Biol. 2014;35(3):2103-2109.

9. Zhou YX, Yang ZM, Feng J, et al. High plasma D-dimer level is associated with decreased survival in patients with lung cancer: a metaanalysis. Tumour Biol. 2013;34(6):3701-3704.

10. Wang Z, Fu JK, Diao DM, et al. Plasma D-dimer level in the perioperative period in non-small-cell lung cancer. Thoracic Cancer. 2011; 2(4):207-212

11. Buccheri G, Torchio P, Ferrigno P. Plasma levels of D-dimer in lung carcinoma- clinical and prognostic significance. Cancer. 2003;97(12): 3044-3052.

12. Unsul E, Atalav F, Atikcan S, Yilmaz A. Prognostic significance of hemostatic parameters in patients with lung cancer. Respir Med. 2004; 98(2):93-98.

13. Gabazza EC, Taguchi O, Yamakami T, et al. Evaluating the prethrombotic state in lung cancer using molecular markers. Chest. 1993; 103(1):196-200.

14. Komurcuoglu B, Ulusoy S, Gayaf M, Guler A, Ozden E. Prognostic value of plasma D-dimer levels in lung carcinoma. Tumori. 2011;97(6): 743-748.

15. Taguchi O, Gabazza EC, Yasui H, Kobayashi T, Yoshida M, Kobayashi H. Prognostic significance of plasma D-dimer levels in patients with lung cancer. Thorax. 1997;52(6):563-565.
OncoTargets and Therapy

\section{Publish your work in this journal}

OncoTargets and Therapy is an international, peer-reviewed, open access journal focusing on the pathological basis of all cancers, potential targets for therapy and treatment protocols employed to improve the management of cancer patients. The journal also focuses on the impact of management programs and new therapeutic agents and protocols on

\section{Dovepress}

patient perspectives such as quality of life, adherence and satisfaction. The manuscript management system is completely online and includes a very quick and fair peer-review system, which is all easy to use. Visit http://www.dovepress.com/testimonials.php to read real quotes from published authors. 